\title{
Healthcare Perceptions of Injectable Therapies for Diabetes Mellitus Type 2
}

\author{
Joy Dugan, MPH, PA-C* \\ Touro University, USA \\ *Corresponding author: Joy Dugan, Associate Program Director, Joint MSPAS/MPH Program, Touro University, California, USA, Fax: 7076385891; Tel: \\ 7076385874; Email: joy.dugan@tu.edu
}

Submission: 監June 09, 2018; Published: 㘹 July 23, 2018

\begin{abstract}
Diabetes mellitus is considered a global epidemic, with financial impacts beyond the cost of treatment. Multiple treatment options are available; however, many healthcare providers lack knowledge or face perceived barriers to prescription. While the American Diabetes Association publishes yearly guideline updates for the management and care of diabetes, many health care providers are unfamiliar with these guidelines. These guidelines recommend insulin and other inject able therapies early in the disease progression, yet the DAWN study demonstrated that physicians delay the initiation of insulin therapy. This paper will review the knowledge gaps, health care provider barriers, and perceptions of inject able therapies. From this review, more knowledge is needed by prescribers in the initiation and management of injectable therapies to help patients successfully reach glycemic targets.
\end{abstract}

\section{Introduction}

As of 2015, diabetes mellitus affects over 23 million Americans [1], with the number of individuals with diabetes mellitus is expected to rise over $54 \%$ to over 54.9 million by 2030 in the United States [2]. Unfortunately, this is a global epidemic, as the [3] estimates diabetes will be the seventh leading cause of death in the world by 2030. Type 2 diabetes mellitus (T2DM), which is often related to lifestyle choices, comprises nearly $95 \%$ of all cases [1]. The future societal affect of T2DM expands beyond fiscal cost. Because the disease causes multiple complications and co morbidities, there will be a global impact on work, school, family life, and psychosocial health.

While T2DM is one of the most common reasons for seeking medical care [1], healthcare providers have a disparity of knowledge in T2DM its management. The American Diabetes Association (ADA) [3] publishes yearly standards of medical care for diabetes that serve as a resource and gold standard for providers' medical decision making internationally [4]. Previous research determined that most providers are not always up to date on the ADA Standards of Care [5]. However, evidence shows this knowledge gap is improving from in among primary care providers [6]. Thus, providers could be rendering care that is either outdated or lacks an evidentiary basis.

The management of patients with T2DM can be difficult due to individual patient characteristics. This includes health and general literacy, numeracy, co morbidities, duration of diagnosis and age [3]. The multidimensional care of T2DM requires providers to follow guidelines and consider individualization of goals to meet the individual patient's healthcare goals. Ultimately, this requires providers to very knowledgeable about both diabetes and the barriers to the daily requirements required for successful management of T2DM.

The The ADA recommends insulin initiation in patients with T2DM who are not achieving glycemic goals (typically haemoglobin A1c below 7.0\% without hypoglycaemia) despite oral medications and lifestyle changes. If at time of diagnosis of T2DM the $\mathrm{A} 1 \mathrm{c}$ is greater than or equal to $10 \%$ and/or symptomatic for hyperglycaemic, then insulin should be initiated [3]. However, many providers do not follow these guidelines. Previous research demonstrates a delay in the initiating insulin of an average 9.2 years from initial T2DM diagnosis with a mean A1c 9.5\% before insulin initiation [7]. Similar results were obtained in an Australian study concluding that despite available effective therapies, most patients with T2DM experience suboptimal glycemic control [8]. Termed clinical inertia [7] or lack of acting on an identified clinical problem, delaying insulin initiation can result in co morbidities and complications if euglycemia is not achieved [3] Primary care providers are central to addressing this disparity in diabetes management. While the ADA has guidelines in place for starting insulin, many providers are insulin phobic to starting and/or titrating. Perceived individual patient barriers to initiation of insulin and lack of provider knowledge of insulin can delay the start of insulin or other inject able therapies for T2DM [9]. This paper will review research regarding provider perceptions, knowledge 
and barriers to prescribing insulin and noninsulin inject able therapies to ultimately improve the glycaemia control of patients with T2DM [3].

\section{Diabetes knowledge of injectables}

Providers may not always know the current evidencebased guidelines for management of T2DM [10]. Based on the ADA Standards of Care, providers may lack the knowledge of the most up to date recommendations for T2DM management Corriere et al $[5,6,10] .383$ physicians, guidelines were followed by $53 \%$ of physicians routinely [11]. The physicians who followed the guidelines had a higher mean diabetes knowledge score compared to non-guideline followers. The guideline followers were also more likely to initiate insulin early. This gap in clinical guideline use demonstrates that disease-specific knowledge influences insulin initiation. Fortunately, guideline knowledge appears to be improving in primary care providers [6].

Williamson et al. evaluated attitudes and practices of T2DM management for various health care professionals including endocrinologists, family practice physicians, internal medicine physicians, primary care nurse practitioners, physician assistants (PAs), certified diabetes educations, retail pharmacists, and hospital pharmacists. [7] Diabetes knowledge questions were focused on ADA standards of care and newer diabetes medications including injectables such as glucagon like peptide 1 (GLP-1) receptor agonists and insulin. Other study points included referral patterns to endocrinologists and certified diabetes educators by primary care providers [7].

In the same study, physicians, nurse practitioners, and physician assistants were comfortable prescribing long-acting basal insulin's, but less comfortable with complex insulin prescriptions and intensification of insulin, to include basal-bolus and premixed insulin prescriptions [6]. Furthermore, there is a gap in knowledge regarding intensification indications for GLP-1 receptor agonists. Both studies by Williamson depicted a disparity in management knowledge and perception, which must be addressed by further education [7].

\section{Lack of formal training}

These knowledge gaps in diabetes management may exist early in a provider's career. In one study of American internal medicine residency programs, diabetes-related knowledge did not greatly improve between the first and last year of training programs [11] A study of over 2,000 physicians determined that approximately two-thirds did not believe their training was adequate for optimal diabetes care [12]. These physicians believed further training was needed in all aspects of diabetes management [12].

\section{Provider attitudes}

The seminal study commonly known as the Study DAWN study or Diabetes, Attitudes, Wishes, and Needs Study examined the correlates of patient and provider attitudes toward insulin therapy [13]. This international study of 13 countries examined both T2DM patients $(n=2,061)$ and diabetes care providers (nurses $=1,109$ and physicians $=2,681$ ) attitudes toward insulin therapy. The authors determined that $50 \%$ of healthcare providers delay initiation of insulin until it is absolutely necessary. In comparison, specialists are less likely to delay both oral anti diabetic medications and insulin therapy. American health care providers were more likely to delay insulin initiation compared to their international counterparts. Of the 13 countries included in this study, only Japan and India were more likely to delay prescription. Thus, health care systems and culture impact the decision to initiate insulin. The DAWN study concluded that, Americans had "the lowest in perceived insulin efficacy and among the highest in insulin self- blame" [14].

The DAWN Study led to further analysis of American primary care physicians' attitudes surrounding insulin initiation by [15] American primary care physicians $(n=505)$ with more than three years of clinical experience were surveyed via the internet. A majority of physicians believed initiation of insulin is a difficult aspect of diabetes management. There is disagreement among study physicians regarding the frequency of self-monitoring blood glucose needed to successfully control diabetes and time needed to train patients using insulin. These two issues can be a barrier for patients using insulin and providers initiating insulin. The DAWN Study highlighted that continuing medical education programs for primary care physicians on initiating and titrating insulin in patients with T2DM because there was no consensus between treatment goals/guidelines and insulin management [14]. In addition to cultural and societal impacts may impact physicians' decision to initiate insulin described psychological insulin resistance (PIR) as the "reluctance providers [have] to prescribe and patients to take insulin" [16]. In a qualitative study, the authors examined insulin therapy perceptions by primary care providers $(n=23)$. In addition to PIR, providers in this study lacked knowledge about insulin injection devices (e.g., needle size, glucometer, etc.). Practice guidelines for T2DM by the ADA discuss various barriers to insulin initiation and risk factors for individuals with co morbidities. For healthcare providers which work with patients with T2DM, more continuing medical education could focus on insulin management.

\section{Challenges of insulin initiation}

Whether perceived or actual challenges, multiple publications describe challenges that providers and patients have with insulin for T2DM management. Table 1 depicts the challenges of insulin initiation for providers.

A. Setting personalized targets [5]

B. Reaching optimal dose of insulin and titration

C. Working jointly with patients [5]

D. Lack of specific training in insulin $[5,17]$

E. Health literacy and numeracy [3]

F. Overcoming religion, cultural barriers [18]

G. Overcoming patient preference to oral medications

H. Psychosocial barriers including patient's self-blame or 
feeling of failure with insulin initiation [19]

I. Limited time and personnel $[17,18]$

J. Provider perception of patient including perceived patient $[18,20]$

\section{K. Lack of continuity of care and system barriers [21,18].}

Other barriers to initiating insulin by providers from a met analysis of 19 articles by Adulaziz et al. [17] includes PCP concerns regarding language barriers, hypoglycaemia, weight gain, and perceived patient fear of injections.

\section{Communication}

Another potential barrier to successful initiation of inject able therapies may be provider to patient communication. In a study of patient and health care provider perspectives, half of the patients reported they described injection related problems to their provider, but did not necessarily receive a solution from their provider. Interestingly, providers reported awareness to the injection related problems including injection site pain. Rubin et al [22]. concluded providers might have communication barriers with patients. Visual aids or having patients demonstrate injections may effectively overcome some of these communication barriers [22].

\section{International perception of primary care providers and insulin initiation}

Proper insulin management is an international obstacle for health care providers. [23] A study of 125 primary care physicians in india demonstrated that newer primary care physicians (fewer than 5 years' experience) were less likely to prescribe insulin than physicians working over 5 years. Newer physicians were statistically less confident initiating insulin $(\mathrm{p}<0.001,0 \mathrm{R}=0.093$ 0.412 ) and changing insulin dosages compared to experienced physicians $(\mathrm{p}<0.001, \mathrm{OR}=0.1060-0489)$. The authors recommended more training for primary care physicians to prescribe, initiate, and titrate insulin. Thus, special training should be given during internship of physicians to better manage diabetes. Another international study of provider's attitudes toward insulin initiation in T2DM found primary care providers are less empowered to manage injectable therapies [5]. Compared to an endocrinologist, primary care providers in Spain waited longer to initiate insulin. If oral medication therapy does not achieve target goals, $62.5 \%$ of endocrinologists versus $42.9 \%$ of primary care providers will initiate insulin within 3 months. Furthermore, primary care providers $(84.8 \%)$ are more likely to check A1c at least twice prior to initiating insulin compared to endocrinologists (58.5\%). Thus, endocrinologists are more likely to initiate insulin based off one A1c reading. Thus, more education is needed for primary care providers in diabetes inject able therapies.

A qualitative study from Malaysia determined cultural specific barriers such as religion and perceived lethality of insulin therapy impacted provider ability to initiate insulin [18]. Furthermore, the authors determined a legacy effect of old insulin guidelines as a barrier to initiating insulin in a timely fashion. [18]. Recommended all healthcare professionals recognize that cultural barriers may exist with insulin management and that many healthcare professionals are outdated in their T2DM knowledge.

\section{Conclusion}

From this literature review, there is an identifiable gap in health care provider knowledge in inject able therapy for T2DM. Primary care providers should seek out continuing medication education focusing specifically on diabetes and inject able management. A study of primary care healthcare providers by demonstrated a willingness to attend diabetes educational programs focused on insulin delivery including devices, insulin titrations, and patient education. Graduate programs and medical schools should increase time spent during the preclinical training educating students on the psychosocial barriers to diabetes that may impact care [24]. In addition, more training on insulin initiation andtitration, along with other inject able therapies is needed to help patients meet their glycaemia goals. Further, new graduates should attend postgraduate continuing medical education to address the disparity in knowledge for diabetes management.

In addition to increasing knowledge through health care provider training, practices should consider adding ancillary staff, such as diabetes educators and clinical pharmacists to an interdisciplinary diabetes treatment team [25]. Diabetes educators and pharmacists can aid healthcare providers in the initiation and titration of insulin. Furthermore, providers must consider the unique needs of patients to include homelessness, social support, visual and dexterity impairments, driving considerations, exercise and physical activity, patients' hypoglycaemia awareness, and literacy levels. primary care providers will remain the first line leaders in management of diabetes. This will be important for the future of health care, if rates for diabetes mellitus continue to increase by the estimated $54 \%$ by 2030 [2]. Healthcare providers must be ready to render treatment using a variety of medications targeting evidence based glycaemia goals.

\section{References}

1. Centers for Disease Control and Prevention (2017) National Diabetes Statistics Report, USA

2. Rowley WR, Bezold C, Arikan Y, Byrne E, Krohe S (2017) Diabetes 2030 insights from yesterday, today and future trends. Popul Health Mang 20(1): 6-12

3. American Diabetes Association (2017) Standards of medical care in diabetes-2017. Diabetes Care 40(Suppl 1): S1-S2.

4. World Health Organization (2017) Diabetes fact sheets, USA.

5. Escalada J, Orozco D, Morillas C, Alvarez F, Gomez F, et al. (2016) Attitudes towards insulin initiation in type 2 diabetes patients among healthcare providers: a survey research. Diabetes Research and Clinical Practice 122: 46-53.

6. Ena J, Casañ R, Lozano T, Leach A, Navarro FJ, et al. (2009) Long-term improvements in insulin prescribing habits and glycaemic control in medical inpatients associated with the instruction of a standardized educational approach. Diabetes Research \& Clinical Practice 85(2): 159165 .

7. Williamson C, Glauser TA, Burton S, Schneider D, Dubois AM, et al. (2014) Health care provider management of patients with Type 2 diabetes mellitus: analysis of trends in attitudes and practices. Postgrad Med 126(3): 145-160.

8. Harris SB, Kapor J, Lank CN, Willian AR, Houston T (2010) Clinical 
inertia in patients with T2DM requiring insulin in family practice. Can Fam Physician 56(12): e418-e424.

9. Davis TM, Davis CU, Bruce DG (2006) Glycaemic levels triggering intensification of therapy in type 2 diabetes in the community: the fremantle diabetes study. Med J Aust 184(7): 325-328.

10. Agarwal G, Nair K, Cosby J, Dolovich L, Levine M, et al. (2008) GPs' approach to insulin prescribing in older patients: a qualitative study. $\mathrm{Br}$ J Gen Pract 58(553): 569-575.

11. Corriere M, Minang LB, Sisson SD, Brancati FL, Kalyani RR (2014) The use of clinical guidelines highlights ongoing educational gaps in physicains' knowledge and decision making related to diabetes. BioMed Central 14: 186.

12. Sisson SD, Bertram A (2010) Changes in knowledge of diabetes guidelines during internal medicine residency training. Primary Care Diabetes 4(3): 193-195.

13. George JT, Warriner D, McGrane DJ, Rozario KS, Price HC, et al. (2011) Lack of confidence among trainee doctors in the management of diabetes: the trainees own perception of delivery of care (TOPDOC) diabetes study. QJM 104(9): 761-766.

14. Peyrot M, Rubin RR, Lauritzen T, Skovlund SE, Snoek FJ, et al. (2005) Resistance to insulin therapy among patients and providers: results of the cross-national diabetes, attitudes, wishes, and needs study. Diabetes Care 28(11): 2673-2679.

15. Hayes RP, Fitzgerald JT, Jacober SJ (2008) Primary care physician beliefs about insulin initiation in patients with type 2 diabetes. Int J Clin Pract 62(6): 860-868.

16. Krall J, Gabbay R, Zickmund S, Hamm ME, Williams KR, et al. (2015) Current perspective on psychological insulin resistance: primary care provider and patient views. Diabetes Technol Ther 17(4): 268-274.

17. Abdulaziz BR, Chenoweth I (2017) Barriers those practitioners face when I initiating insulin therapy in general practice settings and how they can be overcome. World J Diabetes 8(1): 28-39.

18. Lee YK, Lee PY, Ng CJ (2012) A qualitative study on healthcare professionals' perceived barriers to insulin initiation in a multi-ethnic population BMC Fam Pract 13: 28.

19. Ali A, Cheng AY, Yu CH (2015) Breaking down barriers to initiating insulin. Canadian Family Physician 61(5): 445-447.

20. Ratanawongsa N, Crosson JC, Schillinger D, Karter AJ, Saha CK, et al. (2012) Getting under the skin of clinical inertia in insulin initiation: the translating research into action for diabetes (TRIAD) insulin starts project. Diabetes Educ 38(1): 94-100.

21. Hayat A, Shaikh N (2010) Barriers and myths to initiate insulin therapy for type 2 diabetes mellitus at primary health care centers of hyderabad district. World Applied Science 8(1): 66-72.

22. Rubin RR, Peyrot M, Kruger DF, Travis LB (2009) Barriers to insulin injection therapy: patient and health care provider perspectives. Diabetes Educ 35(6): 1014-1022.

23. Chary KV, Swaminathan P (2016) Insulinophobia: existence of an infamous reality in primary health care. Journal of Young Pharmacists 8(2): 141-143.

24. Krall J, Durdock K, Johnson P, Kanter J, Koshinsky J, et al. (2017) Exploring approaches to facilitate diabetes therapy intensification in primary care. Clinical Diabetes.

25. Bin R, Chenoweth I (2017) Barriers that practitioners face when initiating insulin therapy in general practice settings and how they can be overcome. World J Diabetes 8(1): 28-29.
Creative Commons Attribution 4.0 International License

For possible submissions Click Here

\section{Submit Article}

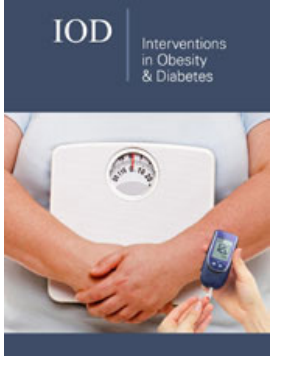

\section{Intervention in Obesity \& Diabetes}

\section{Benefits of Publishing with us}

- High-level peer review and editorial services

- Freely accessible online immediately upon publication

- Authors retain the copyright to their work

- Licensing it under a Creative Commons license

- Visibility through different online platforms 